\title{
Review
}

\section{Many faces of DAMPs in cancer therapy}

\author{
O Krysko ${ }^{1}$, T Løve Aaes ${ }^{2,3}$, C Bachert ${ }^{1}$, P Vandenabeele ${ }^{\star, 2,3,4}$ and DV Krysko*,2,3,4
}

\begin{abstract}
A new concept of immunogenic cell death (ICD) has recently been proposed. The immunogenic characteristics of this cell death mode are mediated mainly by molecules called 'damage-associated molecular patterns' (DAMPs), most of which are recognized by pattern recognition receptors. Some DAMPs are actively emitted by cells undergoing ICD (e.g. calreticulin (CRT) and adenosine triphosphate (ATP)), whereas others are emitted passively (e.g. high-mobility group box 1 protein (HMGB1)). Recent studies have demonstrated that these DAMPs play a beneficial role in anti-cancer therapy by interacting with the immune system. The molecular pathways involved in translocation of CRT to the cell surface and secretion of ATP from tumor cells undergoing ICD are being elucidated. However, it has also been shown that the same DAMPs could contribute to progression of cancer and promote resistance to anticancer treatments. In this review, we will critically evaluate the beneficial and detrimental roles of DAMPs in cancer therapy, focusing mainly on CRT, ATP and HMGB1.
\end{abstract}

Cell Death and Disease (2013) 4, e631; doi:10.1038/cddis.2013.156; published online 16 May 2013

Subject Category: Cancer

\section{Facts}

- Immunogenic cell death (ICD) is characterized by secretion, release or surface exposure of damage-associated molecular patterns (DAMPs).

- Surface-exposed calreticulin (CRT), actively secreted adenosine triphosphate (ATP) and passively released high-mobility group box 1 protein (HMGB1), the key DAMPs of ICD, play a beneficial role in anti-cancer therapy by activating the immune system.

- Depending on the cell death inducer, a specific signaling pathway is activated, leading to CRT surface exposure and ATP secretion.

- Of note, that different conditions of ATP (e.g. different extracellular concentrations) and HMGB1 (e.g. different redox states) could have different biological effects contributing to tumor metastasis and tumor progression.

\section{Open Questions}

- Which redox state of HMGB1 is responsible for the pro- and anti-tumorigenic activities?
- What determines the difference between DAMPs that drive cancer progression and those that inhibit tumor growth?

- Large-scale clinical studies are necessary to determine the prognostic value of ICD associated with DAMP emission in different types of cancers.

More than 20 years ago the 'danger theory' was proposed. This theory explains why potent immune responses are elicited against tissue transplants, ischemia-related injuries, tumors and autoimmune diseases, none of which involve microbial components. ${ }^{1}$ It states that the immune system can distinguish between dangerous and innocuous endogenous signals. In response to trauma, ischemia and other types of tissue and cell damage, and death, certain molecules that perform predominantly non-immunological functions inside the cell are released or secreted from damaged or dead/dying cells or exposed on their surface, thereby initiating an immune response in the absence of infection. These immunostimulatory molecules were later named damage-associated molecular patterns (DAMPs). They can be derived from any compartment of the cell (Figure 1). ${ }^{2,3}$ The modification of DAMPs by proteolysis and oxidation, which often

\footnotetext{
${ }^{1}$ The Upper Airway Research Laboratory, Department of Oto-Rhino-Laryngology, Ghent University Hospital, UZ Gent, MRB, Ghent, Belgium; ${ }^{2}$ Molecular Signalling and Cell Death Unit, Department for Molecular Biomedical Research, VIB, Ghent, Belgium and ${ }^{3}$ Department of Biomedical Molecular Biology, Ghent University, Ghent, Belgium

*Corresponding author: P Vandenabeele or DV Krysko, Molecular Signalling and Cell Death Unit, Department for Molecular Biomedical Research, VIB-Ghent University, Technologiepark 927, Ghent, B-9052, Belgium. Tel: +32 9 3313710; Fax: +32 93313609 (PV); Tel: +32 93313712 ; Fax: +32 93313609 (DVK); E-mail: Peter.Vandenabeele@dmbr.UGent.be or Dmitri.Krysko@dmbr.UGent.be

${ }^{4}$ These authors contributed equally to the work.

Keywords: calreticulin; ATP; HMGB1; immunogenic cell death; TLRs

Abbreviations: AML, acute myeloid leukemia; ATP, adenosine triphosphate; CRT, calreticulin; DAMPs, damage-associated molecular patterns; DC, dendritic cells; elF2 $\alpha$, eukaryotic initiation factor $2 \alpha$; ER, endoplasmic reticulum; HMGB1, high-mobility group box 1 protein; ICD, immunogenic cell death; IL, interleukin; LT, lymphotoxin; MHC, major histocompatibility complex; MYD88, myeloid differentiation primary response gene 88; NLRs, NOD-like receptors; PAMPs, pathogenassociated molecular patterns; PDT, photodynamic therapy; PERK, PKR-like ER kinase; PI3K, phosphoinositide 3-kinase; PS, phosphatidylserine; RAGE, receptor for advanced glycation end products; RLRs, RIG-I-like receptors; ROS, reactive oxygen species; TIM-3, T-cell immunoglobulin domain and mucin domain 3; TLRs, Toll-like receptors; TNF, tumor necrosis factor; Tregs, T regulatory cells

Received 18.12.12; revised 05.3.13; accepted 03.4.13; Edited by G Melino
} 


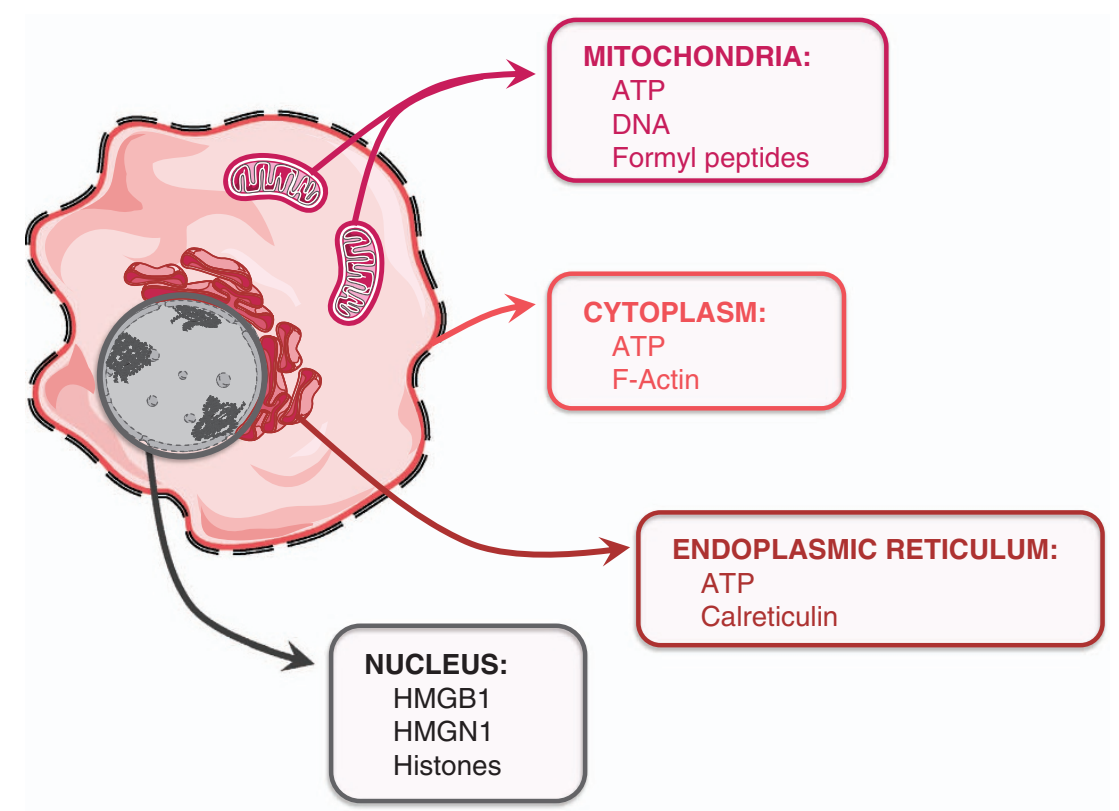

Figure 1 DAMPs are derived from different compartments of the cells. For example, they can come from mitochondria (DNA, formyl peptides and ATP), nucleus (HMGB1, high-mobility group box 1 protein; HMGN1, high mobility group nucleosome binding protein 1; histones), ER (calreticulin and ATP) and cytoplasm (ATP and F-actin) ${ }^{2,74,78}$

accompanies cell death, modulates their immunostimulatory potential. $^{4,5}$ Most of the DAMPs that resemble pathogenassociated molecular patterns (PAMPs) stimulate the immune system through a broad family of membrane-bound or cytoplasmic pattern-recognition receptors, which include Toll-like receptors (TLRs), NOD-like receptors and RIG-I-like receptors. ${ }^{2,3,6-8}$

In the past several years it has been shown that DAMPs can be emitted actively (calreticulin (CRT) and adenosine triphosphate (ATP)) or passively (high-mobility group box 1 protein (HMGB1)) from tumor cells undergoing immunogenic apoptosis, that is, immunogenic cell death (ICD). It has been shown that ICD induction is stressor-dependent ${ }^{9}$ and requires reactive oxygen species (ROS)-based endoplasmic reticulum (ER) stress. ${ }^{10,11}$ Therefore ICD inducers are classified as Type I (e.g. anthracyclines, mitoxantrone, oxaliplatin, cyclophosphamide, UVC and $\gamma$-radiation) or Type II (e.g. hypericin-based photodynamic therapy (PDT)). ${ }^{12}$ Type I ICD inducers trigger ICD through targets that are not associated with the ER but stimulate ICD-associated immunogenicity through secondary or 'collateral' ER stress effects. In contrast, Type II ICD inducers selectively target the ER to induce cell death and ICD-associated immunogenicity in an ER-focused manner. It has been shown that DAMPs have a beneficial role in experimental models of anti-cancer therapy because of their interaction with the immune system. Tumor cells killed in vitro and implanted subcutaneously into syngenic immunocompetent mice can mediate an 'anti-cancer vaccine effect' in the absence of any adjuvants or immunostimulatory substances. ${ }^{11,13,14}$ In this experimental model, considerable proportions of mice inoculated in this way are protected against subsequent re-challenge with live cancer cells and develop fewer tumors at the re-challenge site. It has been shown that surface exposure of CRT, secretion of ATP and passive release of HMGB1 are required for the activation of potent anti-cancer immunity. ${ }^{11,13,14}$ However, in the spontaneous mammary murine tumor model it has been shown that the adaptive immune system is not needed for the therapeutic efficacy of immunogenic chemotherapeutics such as oxaliplatin and doxorubicin. ${ }^{15}$ Also, recent studies have shown that some of these DAMPs (e.g. HMGB1) contribute to the progression of cancer ${ }^{16}$ and promote resistance to anticancer treatments. ${ }^{17-21}$ In this review, we will discuss the beneficial and detrimental roles of DAMPs in cancer therapy, including the mechanisms of emission of three vital DAMPs, namely, surface-exposed CRT, secreted ATP and released HMGB1.

\section{Role of CRT Surface Exposure During ICD in Cancer Treatment}

CRT is a soluble protein in the lumen of the ER, traditionally regarded as a $\mathrm{Ca}^{2+}$ homeostasis regulator and an $\mathrm{ER}$ chaperone. $^{22}$ It is involved in several functions inside and outside the ER, such as regulation of chaperone activity and $\mathrm{Ca}^{2+}$ homeostasis, assembly of the major histocompatibility complex class I molecules, and cellular proliferation and migration.,23 It has been shown that certain anti-cancer modalities induce ICD of tumor cells characterized by surface exposure of CRT before signs of apoptosis (i.e. exposure of PS). ${ }^{13}$ Surface-exposed CRT facilitates tumor antigen presentation and tumor-specific cytotoxic T-lymphocyte responses. It has been shown that the exposure of CRT on the cell surface of cancer cells in response to anthracyclines is dependent on the ER-stress response ${ }^{24}$ associated with ROS production. ${ }^{10,25}$ Several CRT translocation pathways have been described. The first pathway described is induced by anthracyclines and is dependent on PERK-mediated 
eukaryotic initiation factor $2 \alpha$-phosphorylation (elF $2 \alpha-\mathrm{P}$ ), the secretory pathway and caspase-8-mediated BCAP31 (BAP31)-dependent activation of BAX or BAK proteins. ${ }^{10}$ However, recently it has been shown that only PERK, $\mathrm{BAX}$ or BAK and the secretory pathway are required for the surface translocation of CRT in response to hypericinphotodynamic therapy (PDT). ${ }^{11}$ In this case, PERK governed the trafficking of ecto-CRT by regulating the proximal secretory pathway. ${ }^{11}$ elF $2 \alpha$-phosphorylation and caspase-8 signaling were not required for CRT exposure. The pathway that is used for CRT translocation strongly depends on the apoptotic stage during which the exposure takes place. ${ }^{12}$ Indeed, either knockdown of CRT or vaccination of mice with cells deficient in any of the proteins required for CRT exposure reduced the immunogenicity of the cancer cells. ${ }^{11,13}$ All these data indicate that cancer cells undergoing ICD induce protective immunity against the viable cancer cells in the prophylactic anti-cancer vaccination models in mice.

But what about the role of surface-exposed CRT in anticancer treatment in humans, where the situation could be different? It has been shown that anthracycline treatment of human prostate cancer, ovarian cancer and acute lymphoblastic leukemia cell lines (and also primary tumor cells) induces key features of ICD (such as CRT exposure and release of HMGB1) like those in mouse cancer cells. ${ }^{26}$ The authors showed that the cells undergoing ICD induced maturation of dentritic cells (DCs), which stimulated tumorspecific IFN- $\gamma$-producing T cells. Another study showed that CRT exposure correlates with the therapeutic benefit of vaccination with DCs pulsed with primary lymphoma cells undergoing ICD (triggered by heat shock, $\gamma$-irradiation and ultraviolet C-light) in indolent non-Hodgkin's lymphoma patients. ${ }^{27}$ However, leukemic cells isolated from some patients with acute myeloid leukemia (AML) exhibited CRT surface exposure regardless of chemotherapy, and this exposure was not modulated by in vivo chemotherapy, including anthracyclines. ${ }^{28}$ The authors also detected high levels of exposed CRT on malignant myeloblasts, and the level was positively correlated with the ability of autologous $\mathrm{T}$ cells to secrete IFN- $\gamma$ in response to DCs, suggesting that the presence of CRT on the surface of leukemia cells facilitates cellular anti-cancer immune responses in AML patients. Apoptotic AML cells collected during in vivo therapy with all-trans retinoic acid showed increased exposure of CRT during spontaneous in vitro apoptosis, suggesting that in vivo pharmacotherapy can induce ICD. ${ }^{29}$ But the authors detected a wide variation of the level of CRT exposure between patients, which probably depends on individual patient characteristics. ${ }^{29}$ It has also been shown that serum CRT levels are significantly higher in lung cancer patients after chemotherapy compared to untreated patients. ${ }^{30}$ However, in this study correlation of CRT with efficacy of anti-cancer therapy was not examined. In conclusion, there is still no conclusive clinical data on the association between CRT surface exposure and favorable outcome of anti-cancer therapy. Large-scale studies are needed to determine the prognostic value of immunogenic cell death associated with surface translocation/secretion of CRT in patients suffering from different types of cancers.

\section{Role of Extracellular Emission of ATP During ICD in Cancer Treatment}

During the past few years, it has become clear that cells undergoing different types of cell death passively release or actively secrete ATP. ${ }^{2,11,31-33}$ Several mechanisms of ATP secretion in dying/dead/stressed cells have been reported. ${ }^{11,34-36}$ Like the exposure of CRT, the mechanism for ATP secretion in ICD strongly depends on the apoptotic stage and the type of stress or cell death stimulus that induces ICD. ${ }^{12}$ In PDT-induced ICD, ATP was actively secreted from cells during the pre-apoptotic stage, and this secretion was dependent on the classical as well as the PERK-regulated secretory pathway and PI3K-dependent exocytosis, but it was independent of BAX/BAK. ${ }^{11}$

It has been shown that ATP released from dying tumor cells is required for the immune response to cancer cells. ${ }^{37}$ Cancer cells undergoing ICD in response to anthracycline secrete ATP in an autophagy-dependent manner. ${ }^{32,35,36}$ The authors showed that suppression of autophagy inhibited the early apoptotic secretion of ATP from dying cells killed by chemotherapeutics and compromised the tumor-specific immune response in vivo (Figure 2). ${ }^{32,35,36}$ Although all these data suggest that ATP functions as an efficient adjuvant in anti-cancer treatment, no published clinical trials have confirmed this yet.

It is important to note that extracellular ATP, besides acting as a DAMP that stimulates anti-tumor immune responses, can also function as a 'find me' signal facilitating rapid attraction of antigen-presenting cells to sites of extensive apoptotic cell death. ${ }^{31}$ It has been reported that extracellular ATP is involved in the regulation of cell migration of $\mathrm{DCs}^{38-40}$ and also prostate cancer cells. ${ }^{41}$ Thus, by stimulating cell migration (e.g. cancer cells), extracellular ATP could also modulate cancer invasion and metastasis and thereby have a negative effect on anti-cancer treatment. This possibility has to be tested in experimental cancer models.

Extracellular ATP can also stimulate cell proliferation ${ }^{42}$ and it could be a source of immunosuppressive agents such as adenosine. ${ }^{12}$ Pro-inflammatory ATP can be hydrolyzed to immunosuppressive adenosine, ${ }^{43,44}$ which could lead to immune suppression and development of a tumor-promoting microenvironment that reduces the efficacy of anti-tumor immune responses (Figure 2). ${ }^{44-46}$ Another interesting topic for future research is to understand the factors or conditions that determine the biological responses of cells to extracellular ATP. The concentration of extracellular ATP might be an important determinant of the final outcome: it has been shown that different concentrations of extracellular ATP could have different biological effects. ${ }^{47}$ For example, $250 \mathrm{nM}$ extracellular ATP does not modulate Treg functions, whereas at $1 \mathrm{mM}$ it 'turns on' $\mathrm{T}$ regulatory cells (Tregs) and stimulates their proliferation and immunosuppressive ability in a contact-dependent manner. ${ }^{47}$ The stimulation of Tregs by ATP may also represent a mechanism by which tumors avoid the immune system. In addition, it has also been shown that under conditions that cause prolonged release of low amounts of ATP, this nucleotide has a more subtle modulatory function, inducing a distorted DC maturation and diminishing the ability of mature DCs to initiate type 1 immune responses. ${ }^{40,48}$ 


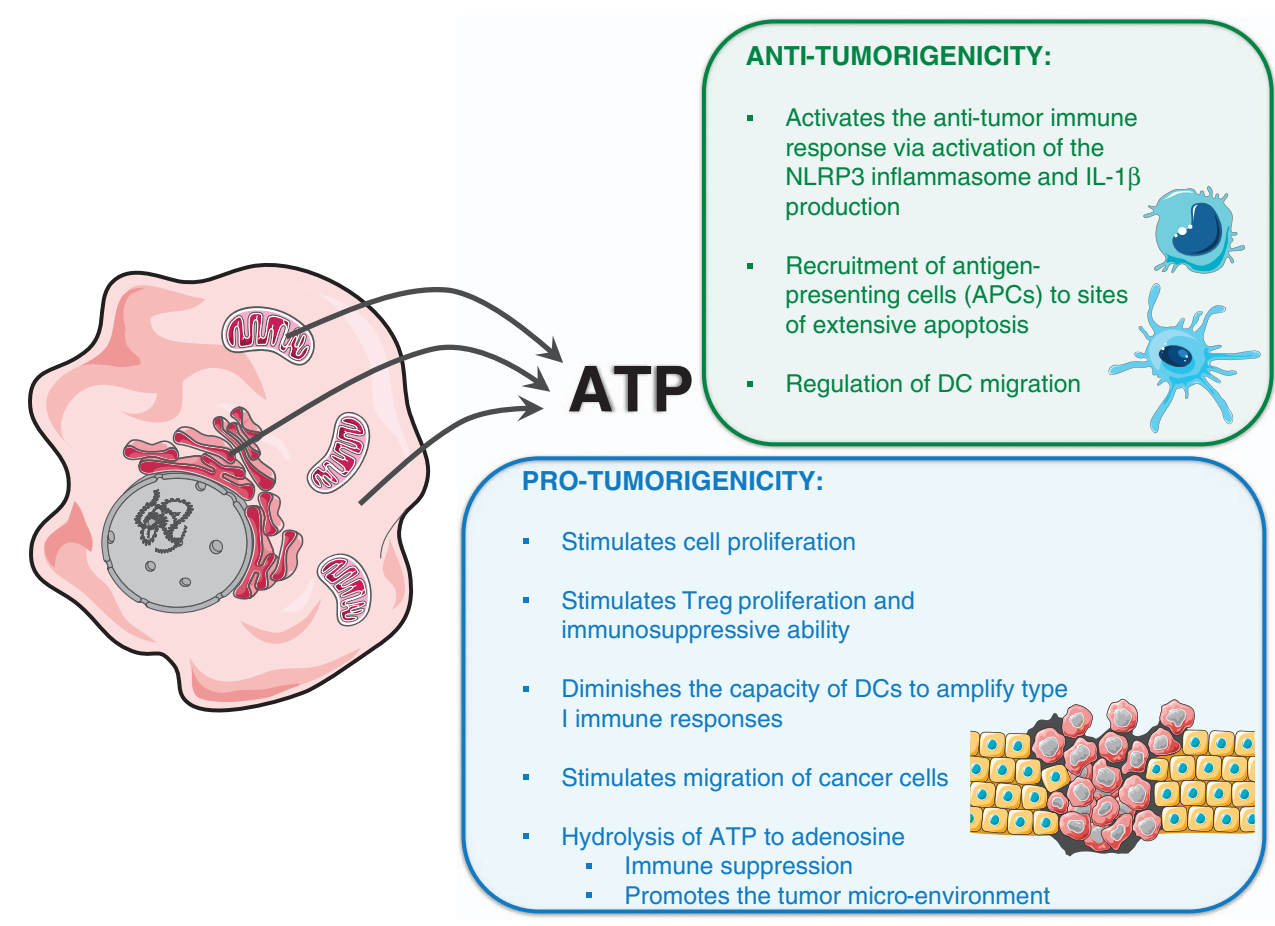

Figure 2 ATP is actively secreted by dying tumor cells in the early apoptotic stage and could be involved in pro- and anti-tumorigenic activities

All these add another angle of complexity to the role of ATP in immunogenicity.

\section{Role of Extracellular HMGB1 in Cancer Treatment}

HMGB1 is a non-histone chromatin-binding protein expressed constitutively by all eukaryotic cells. In the nucleus it mediates different functions, such as stabilization of nucleosomes, DNA repair and recombination, and transcription. ${ }^{49}$ Although the nuclear function of HMGB1 was described in $1975,{ }^{50}$ its extracellular immunomodulatory role was discovered only 24 years later. ${ }^{51}$ The authors found that HMGB1 was secreted as a cytokine by cultured macrophages after stimulation with endotoxin, TNF or IL-1, and that administration of antibodies against HMGB1 attenuated endotoxin lethality in mice. ${ }^{51}$ This study for the first time pointed to a previously unrecognized immunomodulatory role of HMGB1 in experimental mouse models of sepsis and in septic patients. It is now well established that extracellular HMGB1 participates in many biological processes, such as angiogenesis, myogenesis, chemotaxis and wound healing. ${ }^{52-59}$ To fulfill its functions, extracellular HMGB1 binds to various receptors, including TLR2, TLR4, TLR9 and the receptor for advanced glycosylation end products (RAGE). ${ }^{60}$ Further down we will analyze its pro- and anti-tumorigenic activities and emphasize that HMGB1 is one of the DAMPs that have dual and opposite effects on cancer treatment. In cancer therapy, HMGB1 is a double-edged sword (Figure 3).

HMGB1 is associated with cell injury (and acts as a DAMP). Initially, it was proposed that HMGB1 is passively released only from necrotic cells, whereas apoptotic and secondary necrotic cells retain it in the nucleus. ${ }^{61}$ However, it has become clear that most anti-cancer agents and inducers of apoptosis and ICD can promote HMGB1 release. It has been shown that extracellular HMGB1 is required for the immunogenicity of ICD. ${ }^{62}$ These authors used a prophylactic tumor vaccination model, in which immunization of mice with HMGB1 depletes CT26 cancer cells or co-injection of antiHMGB1 antibody compromises the ability of mice to resist rechallenge with live CT26 cancer cells. An effective immune response against cancer cells undergoing ICD requires that DCs have functional TLR4 and intact signaling through its adaptor MYD88 so that antigen from dying tumor cells can be processed and cross-presented efficiently. ${ }^{62}$ Retrospective clinical analysis confirmed these data. In breast cancer patients, loss-of-function single-nucleotide polymorphism (SNP; Asp299Gly) in the T/r-4 gene (reduces binding of HMGB-1 to TLR-4) correlated with early relapse after anthracycline treatment. $^{62}$ In addition, it was recently shown that levels of HMGB1 increase significantly in the plasma of breast cancer patients who respond to neoadjuvant chemotherapy with epirubicin/docetaxel, but not in non-responders. $^{63}$ Similarly, loss-of-function SNP mutation in the TIr-4 gene (Thr399lle) was associated with the worst overall survival of patients with head and neck squamous cell carcinomas after anthracycline administration ${ }^{64}$ and of patients with colorectal cancer receiving oxaliplatin-based therapy. ${ }^{65}$ Also, several other studies pointed to the contribution of extracellular HMGB1 to the efficacy of anti-cancer treatment. For example, it has been shown that HMGB-1 released from dying tumor cells treated with adenoviral vector, radiation and temozolomide led to infiltration of DCs and to regression of TLR-2-dependent brain tumors in a mouse model. ${ }^{66}$ Although all these studies point to the anti-cancer role of HMGB1, it is necessary to mention the other face of HMGB1: its pro-tumorigenic properties. 


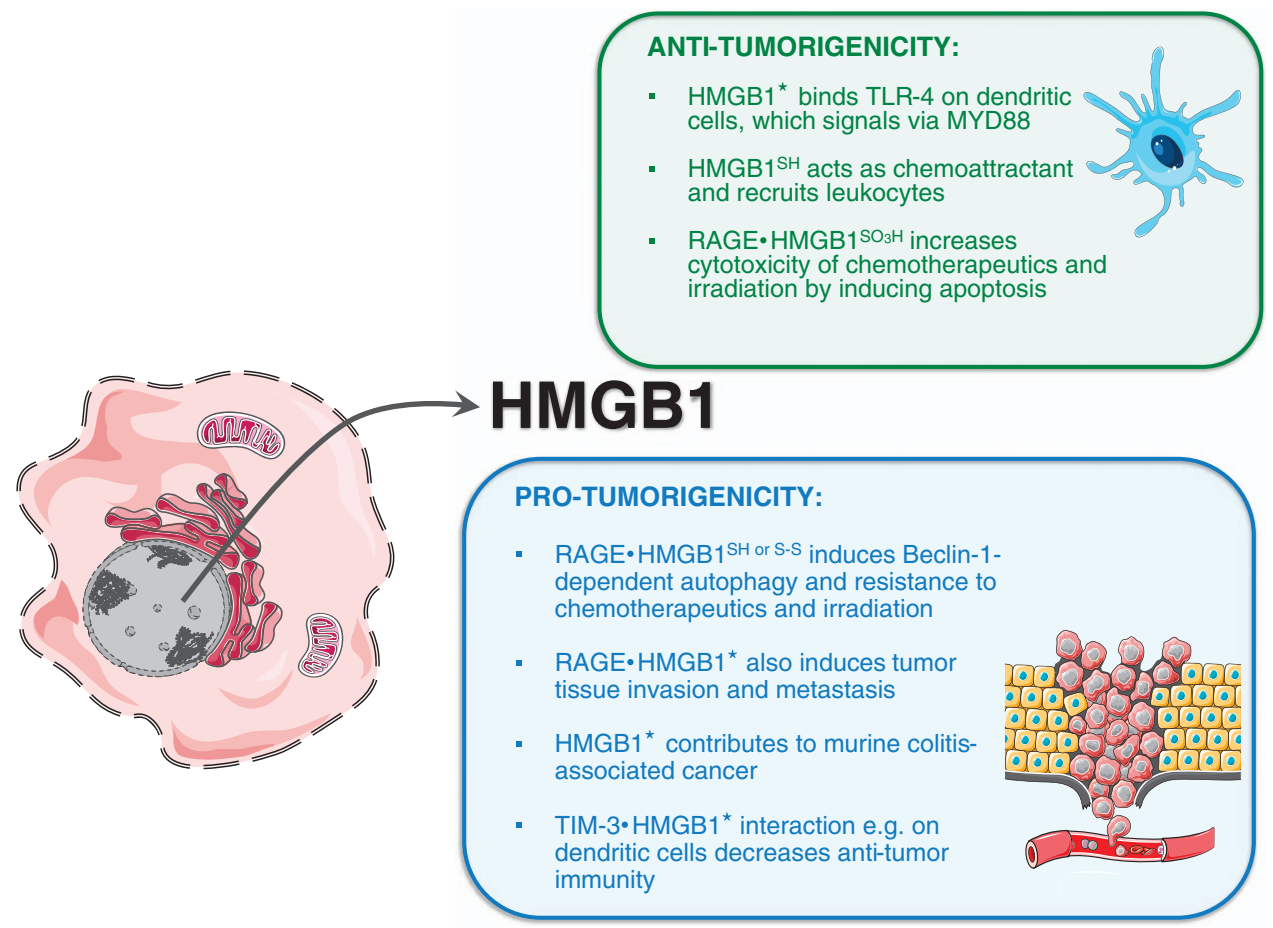

Figure 3 Passive release of HMGB1 from the nucleus of tumor cells during the late stages of apoptotis (e.g. secondary necrosis) induces both pro- and anti-tumorigenic activities, which may depend on the redox state of HMGB1. The redox states are indicated by SH (fully reduced), S-S (disulfide bonds), $\mathrm{SO}_{3} \mathrm{H}$ (oxidized) and $\star$ (unknown)

Several studies have indicated that HMGB1 is involved in tumor tissue invasion and metastasis. It has been shown that blockade of RAGE-HMGB1 decreased growth and metastasis of both implanted tumors and tumors developing spontaneously in susceptible mice. ${ }^{67}$ HMGB1 also mediates the development of murine colitis and colitis-associated cancer. ${ }^{68}$ The authors showed in the colitis-associated cancer model that a neutralizing anti-HMGB1 antibody decreased tumor incidence and size. Recently, it has been shown that the HMGB1 released from dying cells is critical for tumor progression in an established mouse model of prostate cancer. In this model, HMGB1 was required for the activation and intratumoral accumulation of T cells expressing cytokine lymphotoxin- $\alpha 1 \beta 2$ (LT) on their surface. ${ }^{16}$ These tumoractivated $T$ cells were essential for promoting the progression of preneoplasia to invasive carcinoma in an LT $\beta$ receptordependent manner. ${ }^{16}$ Extracellular HMGB1 enhances regrowth and metastasis of cancer cells that have survived chemotherapy. ${ }^{69}$ Another study showed that HMGB1 could decrease anti-tumor immunity via interaction with T-cell immunoglobulin domain and mucin domain 3 (TIM-3). ${ }^{20}$ Tumor-associated DCs in mouse tumors and cancer patients showed strong expression of TIM-3, which interacted with HMGB1 and in that way decreased the therapeutic efficacy of DNA vaccination by diminishing the immunogenicity of DAMPs (e.g. nucleic acids) released from dying cancer cells. Moreover, the authors showed that cisplatin, a nonimmunogenic chemotherapeutic, ${ }^{70}$ might compromise the innate anti-tumor responses of DCs by acting together with TIM-3-dependent inhibitor pathways. ${ }^{20}$
All these various functions of HMGB1 could be partially explained by a switching among mutually exclusive redox states. Recent studies have found that reduced cysteines make HMGB1 a chemoattractant, whereas a disulfide bond makes it a proinflammatory cytokine, and further cysteine oxidation to sulfonates mediated by ROS abrogates both activities. ${ }^{4}$ The different redox states of HMGB1 could be analyzed by liquid chromatography tandem mass spectrometric analysis and by electrophoretic mobility of HMGB1 in the presence and in the absence of dithiothreitol. ${ }^{4}$ It has also been shown that the redox state of extracellular HMGB1 critically regulates the autophagic response to anti-cancer agents and thereby influences anti-tumor efficacy. Reducible HMGB1 binds to RAGE, induces Beclin-1-dependent autophagy, and promotes resistance to chemotherapeutic agents or ionizing radiation, while oxidized HMGB1 increases the cytotoxicity of these chemotherapeutics via induction of apoptosis. $^{71}$

From one point of view all these modifications could occur after the release of HMGB1 within the injured tissues. A possible scenario was proposed for muscle injury: ${ }^{4}$ all-thiolHMGB1 is released first to recruit leukocytes, which in turn produce disulfide-HMGB1 directly by secretion and/or indirectly by ROS-mediated partial oxidation of extracellular HMGB1. Sustained ROS production induces the terminal oxidation of HMGB1, which gets inactivated during the resolution of inflammation. However, the extracellular redox state in cancer may be highly variable. ${ }^{72}$ Different cancer cell types or different stages of progression of the same cancer cell type might generate unique extracellular redox states. ${ }^{72}$ 
This redox state variability associated with cancer cells may partially explain the diversity of HMGB1 effects in anti-tumour immunity. ${ }^{12}$

But from another point of view, modification of HMGB1 (and possibly of other DAMPs) could be caused by activation of a certain biochemical pathway during a specific cell death modality. For example, it has been shown that caspase activity in apoptosis is responsible for modification of the immunogenic form of HMGB1 into the non-immunogenic oxidized HMGB1 form. ${ }^{73}$ In fact, the biochemical processes activated during the different cell death modalities (e.g. in apoptosis versus necroptosis) may profoundly affect the composition and properties of the released DAMPs. ${ }^{74}$

It is also important to take into account that properties of the intrinsic tumor microenvironment, such as the hypoxia often present within tumors, ${ }^{75}$ could modify the action of ICD stressors and modulate the immunomodulatory properties of DAMPs. It was recently shown that hypoxia leads to HMGB1 release, which contributes to tumor invasiveness. ${ }^{76}$ It is well known that hypoxic conditions lead to increased production of ROS, which not only mediate hypoxia-induced HMGB1 release ${ }^{77}$ but could also modify the redox state of HMGB1. However, in these studies ${ }^{71,76,77}$ no distinction was made between all-thiol-HMGB1 and disulfide-HMGB1. It is important to analyze whether these three different redox states of HMGB1 (all-thiol-HMGB1, disulfide-HMGB1 and oxidized HMGB1) can explain the different functions of HMGB1 in anti-cancer treatment.

\section{Future Perspectives}

The insights from the last several years increasingly support the idea that DAMPs represent one of the main characteristics of ICD that are required to induce anti-tumor immunity. Most studies are focusing on experimental mouse models, but it is necessary to explore the possibility of designing large-scale studies in order to determine the prognostic value of ICD associated with DAMP emission in patients suffering from different types of cancers. But it should be kept in mind that under certain conditions, the presence of DAMPs in the tumor microenvironment can promote tumor metastasis and progression. The main question concerns the difference between DAMPs that drive cancer progression and those that inhibit tumor growth. To answer that question, it will be essential to characterize the post-translational modifications of DAMPs, the chemotherapeutic drugs, and the types of tumors and their microenvironment.

\section{Conflict of Interest}

The authors declare no conflict of interest.

Acknowledgements. We thank Dr. A Bredan for editing the manuscript. This work was supported by project grants from the Fund for Scientific Research Flanders (FWO-Vlaanderen, G.0728.10, 3G060713, 3G0A5413 to DVK; 3 G067512 to DVK and OK; G.0642.10N to OK and $C B$ ), by an individual research grant from FWO-Vlaanderen (31507110 to DVK) and by the Federal Research Programme (IAP 7/30 to CB). DVK is a senior postdoctoral researcher and TLA is a doctoral fellow, both paid by fellowships from FWO-Vlaanderen. Vandenabeele's group is supported by VIB, Ghent University (GROUP-ID Consortium of the UGent MRP initiative), FWO-Vlaanderen (G.0875.11, G.0973.11, G.0A45.12N), Federal
Research Programme (IAP 7/32), European Research Programme FP6 ApopTrain (MRTN-CT-035624), FP7 Apo-Sys 200767, and the Euregional PACTII. PV holds a Methusalem Grant (BOF09/01M00709) from the Flemish Government.

1. Matzinger P. Tolerance, danger, and the extended family. Annu Rev Immunol 1994; 12 : 991-1045.

2. Krysko DV, Agostinis $P$, Krysko $O$, Garg AD, Bachert $C$, Lambrecht $B N$ et al. Emerging role of damage-associated molecular patterns derived from mitochondria in inflammation. Trends Immunol 2011; 32: 157-164.

3. Garg AD, Nowis D, Golab J, Vandenabeele P, Krysko DV, Agostinis P. Immunogenic cell death, DAMPs and anticancer therapeutics: an emerging amalgamation. Biochim Biophys Acta 2010; 1805: 53-71.

4. Venereau E, Casalgrandi M, Schiraldi M, Antoine DJ, Cattaneo A, De Marchis F et al. Mutually exclusive redox forms of HMGB1 promote cell recruitment or proinflammatory cytokine release. J Exp Med 2012; 209: 1519-1528.

5. Yang $\mathrm{H}$, Lundback $\mathrm{P}$, Ottosson L, Erlandsson-Harris $\mathrm{H}$, Venereau E, Bianchi ME et al. Redox modification of cysteine residues regulates the cytokine activity of high mobility group box-1 (HMGB1). Mol Med 2012; 18: 250-259.

6. Zitvogel L, Kepp O, Kroemer G. Decoding cell death signals in inflammation and immunity. Cell 2010; 140: 798-804.

7. Palm NW, Medzhitov R. Pattern recognition receptors and control of adaptive immunity. Immunol Rev 2009; 227: 221-233.

8. Krysko DV, Kaczmarek A, Krysko O, Heyndrickx L, Woznicki J, Bogaert P et al. TLR-2 and TLR-9 are sensors of apoptosis in a mouse model of doxorubicin-induced acute inflammation. Cell Death Differ 2011; 18: 1316-1325.

9. Dudek AM, Garg AD, Krysko DV, De Ruysscher D, Agostinis P. Inducers of immunogenic cancer cell death. Cytokine Growth Factor Rev 2013; e-pub ahead of print, 4 February 2013. doi: pii: S1359-6101(13)00006-3.10.1016/j.cytogfr.2013.01.005.

10. Panaretakis T, Kepp O, Brockmeier U, Tesniere A, Bjorklund AC, Chapman DC et al. Mechanisms of pre-apoptotic calreticulin exposure in immunogenic cell death. EMBO J 2009; 28: 578-590.

11. Garg AD, Krysko DV, Verfaillie T, Kaczmarek A, Ferreira GB, Marysael T et al. A novel pathway combining calreticulin exposure and ATP secretion in immunogenic cancer cell death. EMBO J 2012; 31: 1062-1079.

12. Krysko DV, Garg AD, Kaczmarek A, Krysko O, Agostinis $P$, Vandenabeele P. Immunogenic cell death and DAMPs in cancer therapy. Nat Rev Cancer 2012; 12: 860-875.

13. Obeid M, Tesniere A, Ghiringhelli F, Fimia GM, Apetoh L, Perfettini JL et al. Calreticulin exposure dictates the immunogenicity of cancer cell death. Nat Med 2007; 13: 54-61.

14. Casares N, Pequignot MO, Tesniere A, Ghiringhelli F, Roux S, Chaput N et al. Caspasedependent immunogenicity of doxorubicin-induced tumor cell death. J Exp Med 2005; 202: 1691-1701.

15. Ciampricotti M, Hau CS, Doornebal CW, Jonkers J, de Visser KE. Chemotherapy response of spontaneous mammary tumors is independent of the adaptive immune system. Nat Med 2012; 18: 344-346.

16. He Y, Zha J, Wang Y, Liu W, Yang X, Yu P. Tissue damage-associated 'danger signals' influence $T$ cell responses that promote the progression of pre-neoplasia to cancer. Cancer Res 2012; 73: 629-639.

17. Tang D, Kang R, Livesey KM, Cheh CW, Farkas A, Loughran P et al. Endogenous HMGB1 regulates autophagy. J Cell Biol 2010; 190: 881-892.

18. Liu L, Yang M, Kang R, Wang Z, Zhao Y, Yu Y et al. HMGB1-induced autophagy promotes chemotherapy resistance in leukemia cells. Leukemia 2011; 25: 23-31.

19. Liu L, Yang M, Kang R, Wang Z, Zhao Y, Yu Y et al. DAMP-mediated autophagy contributes to drug resistance. Autophagy 2011; 7: 112-114.

20. Chiba S, Baghdadi M, Akiba H, Yoshiyama H, Kinoshita I, Dosaka-Akita H et al. Tumorinfiltrating DCs suppress nucleic acid-mediated innate immune responses through interactions between the receptor TIM-3 and the alarmin HMGB1. Nat Immunol 2012; 13: 832-842.

21. Heijmans J, Buller NV, Hoff E, Dihal AA, van der Poll T, van Zoelen MA et al. Rage signalling promotes intestinal tumourigenesis. Oncogene 2012; 32: 1202-1206.

22. Gelebart $\mathrm{P}$, Opas M, Michalak M. Calreticulin, a $\mathrm{Ca}^{2+}$-binding chaperone of the endoplasmic reticulum. Int J Biochem Cell Biol 2005; 37: 260-266.

23. Gold LI, Eggleton P, Sweetwyne MT, Van Duyn LB, Greives MR, Naylor SM et al. Calreticulin: non-endoplasmic reticulum functions in physiology and disease. FASEB $J$ 2010; 24: 665-683.

24. Garg AD, Kaczmarek A, Krysko O, Vandenabeele P, Krysko DV, Agostinis P. ER stressinduced inflammation: does it aid or impede disease progression? Trends Mol Med 2012; 18: $589-598$.

25. Garg AD, Krysko DV, Vandenabeele $P$, Agostinis $P$. The emergence of phox-ER stress induced immunogenic apoptosis. Oncolmmunology 2012; 1: 786-788.

26. Fucikova J, Kralikova P, Fialova A, Brtnicky T, Rob L, Bartunkova J et al. Human tumor cells killed by anthracyclines induce a tumor-specific immune response. Cancer Res 2011; 71: $4821-4833$

27. Zappasodi R, Pupa SM, Ghedini GC, Bongarzone I, Magni M, Cabras AD et al. Improved clinical outcome in indolent B-cell lymphoma patients vaccinated with autologous tumor cells experiencing immunogenic death. Cancer Res 2010; 70: 9062-9072. 
28. Wemeau M, Kepp O, Tesniere A, Panaretakis T, Flament C, De Botton S et al. Calreticulin exposure on malignant blasts predicts a cellular anticancer immune response in patients with acute myeloid leukemia. Cell Death Dis 2010; 1: e104.

29. Fredly H, Ersvaer E, Giertsen BT, Bruserud O. Immunogenic apoptosis in human acute myeloid leukemia (AML): primary human AML cells expose calreticulin and release hea shock protein (HSP) 70 and HSP90 during apoptosis. Oncol Rep 2011; 25: 1549-1556.

30. Liu R, Gong J, Chen J, Li Q, Song C, Zhang J et al. Calreticulin as a potential diagnostic biomarker for lung cancer. Cancer Immunol Immunother 2012; 61: 855-864.

31. Elliott MR, Chekeni FB, Trampont PC, Lazarowski ER, Kadl A, Walk SF et al. Nucleotides released by apoptotic cells act as a find-me signal to promote phagocytic clearance. Nature 2009; 461: 282-286.

32. Martins I, Tesniere A, Kepp O, Michaud M, Schlemmer F, Senovilla L et al. Chemotherapy induces ATP release from tumor cells. Cell Cycle 2009; 8: 3723-3728.

33. Ayna G, Krysko DV, Kaczmarek A, Petrovski G, Vandenabeele P, Fesus L. ATP release from dying autophagic cells and their phagocytosis are crucial for inflammasome activation in macrophages. PLoS One 2012; 7: e40069.

34. Chekeni FB, Elliott MR, Sandilos JK, Walk SF, Kinchen JM, Lazarowski ER et al. Pannexin 1 channels mediate 'find-me' signal release and membrane permeability during apoptosis. Nature 2010; 467: 863-867.

35. Michaud M, Martins I, Sukkurwala AQ, Adjemian S, Ma Y, Pellegatti P et al. Autophagydependent anticancer immune responses induced by chemotherapeutic agents in mice. Science 2011; 334: 1573-1577.

36. Martins I, Michaud M, Sukkurwala AQ, Adjemian S, Ma Y, Shen S et al. Premortem autophagy determines the immunogenicity of chemotherapy-induced cancer cell death Autophagy 2012; 8: 3.

37. Ghiringhelli F, Apetoh L, Tesniere A, Aymeric L, Ma Y, Ortiz C et al. Activation of the NLRP3 inflammasome in dendritic cells induces IL-1beta-dependent adaptive immunity against tumors. Nat Med 2009; 15: 1170-1178.

38. Idzko M, Dichmann S, Ferrari D, Di Virgilio F, la Sala A, Girolomoni G et al. Nucleotides induce chemotaxis and actin polymerization in immature but not mature human dendritic cells via activation of pertussis toxin-sensitive P2y receptors. Blood 2002; 100: 925-932.

39. Myrtek D, Idzko M. Chemotactic activity of extracellular nucleotideson human immune cells. Purinergic Signal 2007; 3: 5-11.

40. Ia Sala A, Sebastiani S, Ferrari D, Di Virgilio F, Idzko M, Norgauer J et al. Dendritic cells exposed to extracellular adenosine triphosphate acquire the migratory properties of mature cells and show a reduced capacity to attract type $1 \mathrm{~T}$ lymphocytes. Blood 2002; 99: $1715-1722$

41. Zhang Y, Gong LH, Zhang HQ, Du Q, You JF, Tian XX et al. Extracellular ATP enhances in vitro invasion of prostate cancer cells by activating Rho GTPase and upregulating MMPs expression. Cancer Lett 2010; 293: 189-197.

42. Ryu JK, Choi HB, Hatori K, Heisel RL, Pelech SL, McLarnon JG et al. Adenosine triphosphate induces proliferation of human neural stem cells: role of calcium and p70 ribosomal protein S6 kinase. J Neurosci Res 2003; 72: 352-362.

43. Robson SC, Sevigny J, Zimmermann H. The E-NTPDase family of ectonucleotidases: structure function relationships and pathophysiological significance. Purinergic Signal 2006; 2: 409-430.

44. Beavis PA, Stagg J, Darcy PK, Smyth MJ. CD73: a potent suppressor of antitumor immune responses. Trends Immunol 2012; 33: 231-237.

45. Ohta A, Gorelik E, Prasad SJ, Ronchese F, Lukashev D, Wong MK et al. A2A adenosine receptor protects tumors from antitumor T cells. Proc Natl Acad Sci USA 2006; 103 : 13132-13137.

46. Pellegatti P, Raffaghello L, Bianchi G, Piccardi F, Pistoia V, Di Virgilio F. Increased level of extracellular ATP at tumor sites: in vivo imaging with plasma membrane luciferase. PLOS One 2008; 3: e2599.

47. Trabanelli S, Ocadlikova D, Gulinelli S, Curti A, Salvestrini V, de Paula Vieira R et al. Extracellular ATP exerts opposite effects on activated and regulatory CD4 + T cells via purinergic P2 receptor activation. J Immunol 2012; 189: 1303-1310.

48. la Sala A, Ferrari D, Corinti S, Cavani A, Di Virgilio F, Girolomoni G. Extracellular ATP induces a distorted maturation of dendritic cells and inhibits their capacity to initiate Th1 responses. J Immunol 2001; 166: 1611-1617.

49. Tang D, Kang R, Zeh HJ 3rd, Lotze MT. High-mobility group box 1 and cancer. Biochim Biophys Acta 2010; 1799: 131-140.

50. Andersson U, Tracey KJ. HMGB1 is a therapeutic target for sterile inflammation and infection. Annu Rev Immunol 2011; 29: 139-162.

51. Wang $\mathrm{H}$, Bloom O, Zhang M, Vishnubhakat JM, Ombrellino M, Che J et al. HMG-1 as a late mediator of endotoxin lethality in mice. Science 1999; 285: 248-251.

52. Palumbo R, Sampaolesi M, De Marchis F, Tonlorenzi R, Colombetti S, Mondino A et al. Extracellular HMGB1, a signal of tissue damage, induces mesoangioblast migration and proliferation. J Cell Biol 2004; 164: 441-449.

53. Schlueter $\mathrm{C}$, Weber H, Meyer B, Rogalla $\mathrm{P}$, Roser K, Hauke $\mathrm{S}$ et al. Angiogenetic signaling through hypoxia: HMGB1: an angiogenetic switch molecule. Am J Pathol 2005; 166: 1259-1263.

54. Mitola S, Belleri M, Urbinati C, Coltrini D, Sparatore B, Pedrazzi M et al. Cutting edge: extracellular high mobility group box-1 protein is a proangiogenic cytokine. J Immuno 2006; 176: 12-15.
55. Sorci G, Riuzzi F, Arcuri C, Giambanco I, Donato R. Amphoterin stimulates myogenesis and counteracts the antimyogenic factors basic fibroblast growth factor and $S 100 \mathrm{~B}$ via RAGE binding. Mol Cell Biol 2004; 24: 4880-4894.

56. Straino S, Di Carlo A, Mangoni A, De Mori R, Guerra L, Maurelli R et al. High-mobility group box 1 protein in human and murine skin: involvement in wound healing. $J$ Invest Dermato 2008; 128: 1545-1553.

57. Degryse B, Bonaldi T, Scaffidi P, Muller S, Resnati M, Sanvito F et al. The high mobility group (HMG) boxes of the nuclear protein HMG1 induce chemotaxis and cytoskeleton reorganization in rat smooth muscle cells. J Cell Biol 2001; 152: 1197-1206.

58. Porto A, Palumbo R, Pieroni M, Aprigliano G, Chiesa R, Sanvito F et al. Smooth muscle cells in human atherosclerotic plaques secrete and proliferate in response to high mobility group box 1 protein. FASEB J 2006; 20: 2565-2566.

59. Chavakis E, Hain A, Vinci M, Carmona G, Bianchi ME, Vajkoczy P et al. High-mobility group box 1 activates integrin-dependent homing of endothelial progenitor cells. Circ Res 2007; 100: 204-212.

60. Yanai H, Ban T, Taniguchi T. High-mobility group box family of proteins: ligand and sensor for innate immunity. Trends Immunol 2012; 33: 633-640.

61. Scaffidi $P$, Misteli T, Bianchi ME. Release of chromatin protein HMGB1 by necrotic cells triggers inflammation. Nature 2002; 418: 191-195.

62. Apetoh L, Ghiringhelli F, Tesniere A, Obeid M, Ortiz C, Criollo A et al. Toll-like receptor 4-dependent contribution of the immune system to anticancer chemotherapy and radiotherapy. Nat Med 2007; 13: 1050-1059.

63. Arnold T, Michlmayr A, Baumann S, Burghuber C, Pluschnig U, Bartsch R et al. Plasma HMGB-1 after the initial dose of epirubicin/docetaxel in cancer. Eur J Clin Invest 2013; 43: 286-291.

64. Bergmann C, Bachmann HS, Bankfalvi A, Lotfi R, Putter C, Wild CA et al. Toll-like receptor 4 single-nucleotide polymorphisms Asp299Gly and Thr399lle in head and neck squamous cell carcinomas. J Transl Med 2011; 9: 139

65. Tesniere A, Schlemmer F, Boige V, Kepp O, Martins I, Ghiringhelli $F$ et al. Immunogenic death of colon cancer cells treated with oxaliplatin. Oncogene 2010; 29: 482-491.

66. Curtin JF, Liu N, Candolfi M, Xiong W, Assi H, Yagiz K et al. HMGB1 mediates endogenous TLR2 activation and brain tumor regression. PLoS Med 2009; 6: e10.

67. Taguchi A, Blood DC, del Toro G, Canet A, Lee DC, Qu W et al. Blockade of RAGE-amphoterin signalling suppresses tumour growth and metastases. Nature 2000; 405: 354-360.

68. Maeda S, Hikiba Y, Shibata W, Ohmae T, Yanai A, Ogura K et al. Essential roles of highmobility group box 1 in the development of murine colitis and colitis-associated cancer. Biochem Biophys Res Commun 2007; 360: 394-400.

69. Luo Y, Chihara Y, Fujimoto K, Sasahira T, Kuwada M, Fujiwara R et al. High mobility group box 1 released from necrotic cells enhances regrowth and metastasis of cancer cells that have survived chemotherapy. Eur J Cancer 49: 741-751.

70. Martins I, Kepp O, Schlemmer F, Adjemian S, Tailler M, Shen S et al. Restoration of the immunogenicity of cisplatin-induced cancer cell death by endoplasmic reticulum stress. Oncogene 2011; 30: 1147-1158.

71. Tang D, Kang R, Cheh CW, Livesey KM, Liang X, Schapiro NE et al. HMGB1 release and redox regulates autophagy and apoptosis in cancer cells. Oncogene 2010; 29: 5299-5310.

72. Chaiswing L, Oberley TD. Extracellular/microenvironmental redox state. Antioxid Redox Signal 2010; 13: 449-465.

73. Kazama H, Ricci JE, Herndon JM, Hoppe G, Green DR, Ferguson TA. Induction of immunological tolerance by apoptotic cells requires caspase-dependent oxidation of highmobility group box-1 protein. Immunity 2008; 29: 21-32.

74. Kaczmarek A, Vandenabeele P, Krysko DV. Necroptosis: the release of damageassociated molecular patterns and its physiological relevance. Immunity 2013; 38: 209-223

75. Harrison L, Blackwell K. Hypoxia and anemia: factors in decreased sensitivity to radiation therapy and chemotherapy? Oncologist 2004; 9: 31-40.

76. Yan W, Chang Y, Liang X, Cardinal JS, Huang H, Thorne SH et al. High-mobility group box 1 activates caspase-1 and promotes hepatocellular carcinoma invasiveness and metastases. Hepatology 2012; 55: 1863-1875.

77. Tsung A, Klune JR, Zhang X, Jeyabalan G, Cao Z, Peng X et al. HMGB1 release induced by liver ischemia involves Toll-like receptor 4 dependent reactive oxygen species production and calcium-mediated signaling. J Exp Med 2007; 204: 2913-2923.

78. Yang D, Postnikov YV, Li Y, Tewary P, de la Rosa G, Wei F et al. High-mobility group nucleosome-binding protein 1 acts as an alarmin and is critical for lipopolysaccharideinduced immune responses. J Exp Med 2012; 209: 157-171.

(c) (i) $\odot$ Cell Death and Disease is an open-access journal published by Nature Publishing Group. This work is licensed under a Creative Commons Attribution-NonCommercialNoDerivs 3.0 Unported License. To view a copy of this license, visit http://creativecommons.org/licenses/by-nc-nd/3.0/ 